\title{
Predictive capacity of indicators of adiposity in the metabolic syndrome in elderly individuals
}

\section{Capacidade preditiva de indicadores de adiposidade sobre a sindrome metabólica em idosos}

\author{
Keila Bacelar Duarte de MORAIS ${ }^{1}$ (D) 0000-0002-4754-3796 \\ Karina Oliveira MARTINHO ${ }^{1}$ (D) 0000-0001-9978-0112 \\ Fernanda Silva FRANCO ${ }^{1}$ (D) 0000-0002-3880-3584 \\ Milene Cristine PESSOA ${ }^{2}$ (D) 0000-0002-1053-5450 \\ Andréia Queiroz RIBEIRO1 (D) 0000-0001-6546-1252
}

\section{A B S T R A C T}

\section{Objective}

To evaluate the predictive ability of adiposity indicators as MetS predictors in elderly individuals.

\section{Methods}

Cross-sectional study enrolled in the Estratégia Saúde da Familia (Family Health Strategy). Anthropometric measurements were measured. Body Mass Index, Waist-Hip Ratio, Waist-Height Ratio, Conicity Index and Body Adiposity Index were calculated. Blood was collected and resting blood pressure was measured. MetS was

\footnotetext{
1 Universidade Federal de Viçosa, Departamento de Nutrição e Saúde, Programa de Pós-Graduação em Ciência da Nutrição. Av. PH Rolfs, s/n., CCB-II, 36570-000, Viçosa, MG, Brasil. Correspondência para/Correspondence to: KBD MORAIS. E-mail: <keila_bacelar@yahoo.com.br>.

2 Universidade Federal de Minas Gerais, Escola de Enfermagem, Departamento de Nutrição, Programa de Pós-Graduação em Nutrição e Saúde. Belo Horizonte, MG, Brasil. Article based on the master's thesis of KBD MORAIS, entitled "Capacidade preditiva de indicadores de adiposidade sobre o risco cardiometabólico em idosos de Viçosa (MG)”. Universidade Federal de Viçosa; 2014.

Support: Coordenação de Aperfeiçoamento de Pessoal de Nível Superior.
}

Como citar este artigo/How to quote this article

Morais KBD, Martinho KO, Franco FS, Pessoa MC, Ribeiro AQ. Predictive capacity of indicators of adiposity in the metabolic syndrome in elderly individuals. Rev Nutr. 2018;31(2):199-209. http://dx.doi.org/10.1590/1678-98652018000200006 
classified according to the harmonizing criteria. The predictive ability of anthropometric variables was evaluated using Receiver Operating Characteristic curves.

\section{Results}

Regarding male individuals, our research indicates that the BMI, Waist-Height Ratio and Waist Hip Ratio are better predictors and they are equivalent to each other. As for female individuals, results show that the Body Mass Index and Waist-Height Ratio are better predictors and equivalent to each other.

\section{Conclusion}

Waist-Height Ratio and Body Mass Index are good MetS predictors for elderly individuals, especially among men. More research in this area is important. Comitê de Ética em Pesquisa com Seres Humanos da Universidade Federal de Viçosa. (Viçosa University Ethics Committee in Research with Human Beings) (nº39/2011).

Keywords: Aging. Cutoff Points. Elderly individuals. Metabolic Syndrome. Obesity.

\section{R E S U M O}

\section{Objetivo}

Este estudo objetivou avaliar a capacidade preditiva dos indicadores de adiposidade como preditores da Síndrome Metabólica em idosos.

\section{Métodos}

Trata-se de estudo transversal com idosos inscritos na Estratégia Saúde da Família. Foram aferidas medidas antropométricas e calculados o Índice de Massa Corporal, a Relação Cintura-Quadril, a Relação Cintura-Estatura, o Índice de Conicidade e o Índice de Adiposidade Corporal. Foi coletada amostra sanguínea e aferida a pressão arterial de repouso. A Síndrome Metabólica foi classificada de acordo com os Critérios Harmonizados. A capacidade preditiva das variáveis antropométricas foi avaliada por meio das curvas Receiver Operating Characteristic.

\section{Resultados}

Para o sexo masculino, o Índice de Massa Corporal, a Relação Cintura-Estatura e a Relação Cintura-Quadril são melhores preditores e equivalentes entre si. Já para o sexo feminino, os dois primeiros são melhores preditores e equivalentes entre si.

\section{Conclusão}

Concluiu-se que o Índice de Massa Corporal e a Relação Cintura-Estatura são bons preditores da Síndrome Metabólica em indivíduos idosos, especialmente entre homens. Mais investigações nesse âmbito se fazem importantes. Comitê de Ética em Pesquisa com Seres Humanos da Universidade Federal de Viçosa. (nº 039/2011).

Palavras-chave: Envelhecimento. Pontos de Corte. Idosos. Síndrome Metabólica. Obesidade.

\section{NTRODUCTIO N}

The Metabolic Syndrome (MetS) is recognized by the occurrence of multiple metabolic abnormalities $[1,2]$. Although there is little data available on the prevalence of MetS in the elderly population both in Brazil and in a global scale [3], it is known that the prevalence increases with age $[2,3]$. Detecting metabolic disorders - preferably early - is essential to prevent and delay the onset of cardiovascular diseases, including MetS, and to guide their treatment [4-7].
Studies have suggested the use of body measurements to assess adiposity $[4,8]$. This is an important fact, since age-associated increases in central fat distribution correlate with metabolic and cardiovascular abnormalities $[3,6]$.

In addition to classic measures and related indices such as Body Mass Index (BMI), Waist Circumference (WC) and Waist-Hip Ratio (WHR), different studies have suggested and used Conicity Index (Col), Waist-Height Ratio (WHeR), Body Adiposity Index (BAl), as well as other measures as adiposity indicators in elderly 
individuals. However, there is still no consensus about which adiposity indicator is the best predictor of cardiovascular events resulting from body fat accumulation within this age group [5,8-11].

Studies have identified associations among adiposity indicators, adverse health events, and cardiometabolic risk in elderly individuals. However, few studies investigating appropriate cutoff points of such indicators as predictors of cardiovascular diseases have been performed, and very few have specifically addressed MetS in elderly individuals $[4,9,12,13]$.

The current study aims to evaluate the predictive capacity of adiposity indicators to predict MetS in elderly men and elderly women and to determine specific cutoff points regarding this population.

\section{METHOD S}

It is a cross-sectional study conducted in all Estratégia Saúde da Família (Family Health Strategy, FHS) units in Viçosa (MG), from August 2011 to June 2012, including its urban and rural areas.

The study fully met the standards regarding research involving human beings, Resolution 196/96 of the National Health Council from 10/10/1996 and the Helsinki Resolution. The research project was approved by the Comitê de Ética em Pesquisa com Seres Humanos da Universidade Federal de Viçosa (Viçosa University Ethics Committee in Research with Human Beings) (nº 039/2011).

The sample size calculation considered a 95\% confidence level, a 65\% MetS prevalence [1] and a 5\% tolerated error. Thus, the sample comprised 331 elderly individuals, to which $20 \%$ was added to cover possible losses, in a total of 398 individuals. The final sample consisted of 402 people. The sample size calculation was performed using Epi-Info 3.5.1 software (CDC - Center of Disease Control and Prevention, Georgia, United State of America).
The inclusion criteria for participation in the study were that the volunteers had to be 60 years old or above, registered in the Family Health Strategy, and that they had to attend the two meetings in conducting the study.

Data collection was performed in all the Family Health Strategy during two meetings. In the first meeting, participants were informed about the research goals and signed the Informed Consent Form. Subsequently, a questionnaire was completed to collect participants' sociodemographic features. Then, anthropometric assessment was obtained.

Weight and height were measured as recommended by the World Health Organization (WHO) [14]. The volunteers' weight was measured using a digital electronic scale from $\operatorname{Kratos}^{\circledR}$ (Kratos Equipamentos Industriais, Cotia, São Paulo, Brazil) of $150 \mathrm{~kg}$ capacity and $50 \mathrm{~g}$ of weight sensitivity. Their height was obtained using the millimetric vertical anthropometer from Welmy ${ }^{\circledR}$, (Welmy, Santa Barbara d'Oeste, São Paulo, Brazil) with a maximum height of $2 \mathrm{~m}$, divided into centimeters and subdivided into millimeters. A trained professional measured the participants' waists and hips three times and calculated the mean value. These measurements were obtained by using a millimeter graduated inextensible tape measure from Cardiomed $^{\circledR}$ (Curitiba, Paraná, Brazil), as recommended by the WHO [15].

From thesemeasurements, theanthropometric indices were calculated: Body Mass Index (BMI), Waist-Hip Ratio (WHR), Waist-to-Height Ratio (WHeR), Conicity Index (Col) and Body Adiposity Index (BAI). The volunteers' nutritional status was classified by their BMI according to Lipschitz [16].

Blood collection was performed in the second meeting to evaluate plasma glucose, High Density Liprotein ( $\mathrm{HDL}$ ) and triglycerides parameters. The volunteers fasted for 12 hours before the blood collection. Resting blood pressure was also measured by indirect auscultation using a stethoscope and a mercury 
sphygmomanometer from $\operatorname{Tycos}^{\circledR}$, model EC 048 (Tyco Fire Products LP, Pennsylvania, United States of America) The VII Brazilian Guidelines on Arterial Hypertension [17] recommendations were followed. Biochemical analyses were performed in the Laboratório de Biofarmacêutica do Departamento de Bioquímica e Biologia Celular Universidade Federal de Viçosa. (Viçosa University - Biopharmaceutical Laboratory of the Department of Biochemistry and Cell Biology).

Elderly individuals were classified as syndromic according to the Joint Interim Statement (JIS) [18] harmonizing criteria. The outcome variable was the presence of three or more than five components of the metabolic syndrome.

Data analysis was initially performed by frequency distribution and estimation of central and dispersion tendencies. The mean values and ratios of sociodemographic and anthropometric variables were compared according to the individual's sex. As for the quantitative variables, a Shapiro-Wilk normality test was carried out. Variables without normal distribution were transformed into a logarithm. Both a student's test and a Pearson's chi-square test were used in this stage, taking under consideration the significance level $=0.05$. The prevalence of changes in MetS components was also estimated according to sex.

The predictive ability of adiposity indicators as well as the cutoff points were established by Receiver Operating Characteristic (ROC) curve analysis. The total Area Under the ROC Curve (AUC) and the respective confidence intervals $(95 \% \mathrm{Cl})$ were also determined. The difference between the curves generated from each indicator was compared using a Z-statistics test. Sensitivity (SE), Specificity (ES), Positive (PPV) and Negative (NPV) predictive values were also calculated for each indicator. The best cutoff point corresponded to the anthropometric indicator value that presented the greatest accuracy. Statistical analyses were conducted through STATA 13.0 software (StataCorp LLC, College Station, Texas, United State of America).
RE S U L T S

Four hundred and two elderly individuals were evaluated, $60.4 \%$ of them were women. Their average age was of $72.8 \pm 7.0$ years among women and $71.2 \pm 7.0$ years among men. The Tables 1 and 2 show the socioeconomic and anthropometric characteristics stratified by sex evaluated in the study.

Table 3 shows the frequency of altered components of MetS and in the adiposity indicators. There was a high frequency of altered biochemical components, especially fasting glucose, HDL and blood pressure. Differences between sexes were statistically significant. WC measurement showed higher levels of alteration in women $(p<0.001)$. Regarding the anthropometric indicators, only $\mathrm{Col}$ and $\mathrm{BAI}$ showed lower levels of alteration among elderly individuals. As for the others, the frequency was high, especially among women, and the differences were significant $(p<0.001)$. The MetS prevalence was $54.8 \%(95.0 \% \mathrm{Cl}: 49.0 \%$ - $59.0 \%$ ), $40.3 \%$ (95\% Cl:32.0\% - 47.0\%) in men and $63.8 \%(95 \% \mathrm{Cl}: 57.0 \%-69.0 \%)$ in women $(p<0.001)$.

Table 4 shows the anthropometric variables predictive ability regarding MetS in both sexes. In men, the evaluation of the predictive ability of adiposity indicators and body composition showed that all the indicators presented good predictive ability; however, BMI, WHeR and WHR were the best predictors and they were equivalent to each other, thus showing a higher area under the ROC curve (AUC).

WheR differed from $\mathrm{Col}$ and $\mathrm{BAI}$, which showed lower predictive capacity and they were equivalent to each other. BMI and WHR differed only from BAI. WheR was considered to be the best predictor. This indicator showed higher Sensitivity (SE), Positive Predictive Value (PPV), Negative Predictive Value (NPV) in MetS identification. Overall, WHeR and BMI were the most sensitive indices; however, PPV values were 
Table 1. Sociodemographic features of the elderly assisted by the Health Strategy Family Program in Viçosa (MG), 2012.

\begin{tabular}{|c|c|c|c|c|c|c|c|}
\hline \multirow{2}{*}{ Variables } & \multicolumn{2}{|c|}{ Total } & \multicolumn{2}{|c|}{ Men } & \multicolumn{2}{|c|}{ Women } & \multirow{2}{*}{$p^{*}$} \\
\hline & $n$ & $\%$ & $\mathrm{n}$ & $\%$ & N & $\%$ & \\
\hline \multicolumn{8}{|l|}{ Marital Status } \\
\hline Married & 228 & 57 & 122 & 76.7 & 106 & 43.6 & $<0.01$ \\
\hline Divorced/ widowed/ single & 174 & 43 & 37 & 23.3 & 137 & 56.4 & \\
\hline \multicolumn{8}{|l|}{ Ethnicity } \\
\hline White & 109 & 27.1 & 41 & 25.8 & 68 & 28 & 0.77 \\
\hline Brown & 196 & 48.7 & 81 & 50.9 & 115 & 7.4 & \\
\hline Black & 97 & 24.2 & 37 & 23,3 & 60 & 24.6 & \\
\hline \multicolumn{8}{|l|}{ Work } \\
\hline Active & 117 & 29.2 & 53 & 33.3 & 64 & 26.6 & 0.14 \\
\hline Not active & 283 & 70,8 & 106 & 66.7 & 177 & 73.4 & \\
\hline \multicolumn{8}{|l|}{ Own housing } \\
\hline Yes & 371 & 92.3 & 147 & 92.3 & 224 & 92.2 & 0.92 \\
\hline No & 31 & 7.7 & 12 & 7.7 & 19 & 7.8 & \\
\hline \multicolumn{8}{|l|}{ Schooling } \\
\hline Illiterate & 111 & 27.6 & 36 & 22.7 & 75 & 30.9 & 0.16 \\
\hline $1-4$ years of study & 234 & 58.2 & 97 & 61 & 137 & 56.4 & \\
\hline 5 or more years of study & 57 & 14.2 & 26 & 16.3 & 31 & 12.7 & \\
\hline
\end{tabular}

Note: *Pearson Chi-Square test.

Table 2. Mean, standard deviation of the anthropometric variables in elderly enrolled in the Family Health Strategy Program in Viçosa (MG), 2012

\begin{tabular}{|c|c|c|c|c|c|}
\hline \multirow{2}{*}{ Variables } & \multicolumn{2}{|c|}{ Men $(n=159)$} & \multicolumn{2}{|c|}{ Women $(n=243)$} & \multirow{2}{*}{$p^{*}$} \\
\hline & Mean & SD & Mean & $\mathrm{SD})$ & \\
\hline Age (years) & 71.2 & 7.0 & 72.8 & 7.0 & 0.02 \\
\hline Weight (kg) & 69.2 & 12.6 & 62.8 & 11.4 & $<0.001$ \\
\hline Height (m) & 1.65 & 6.7 & 1.5 & 6.4 & $<0.001$ \\
\hline BMI $\left(\mathrm{kg} / \mathrm{m}^{2}\right)$ & 25.3 & 4.1 & 27.6 & 4.6 & $<0.001$ \\
\hline$W C(\mathrm{~cm})$ & 92.0 & 11.6 & 94.3 & 11.5 & $<0.001$ \\
\hline $\mathrm{HC}(\mathrm{cm})$ & 94.5 & 6.8 & 98.0 & 8.9 & $<0.001$ \\
\hline WHR & 0.9 & 0.0 & 0.9 & 0.0 & 0.19 \\
\hline Wher & 0.5 & 0.0 & 0.6 & 0.0 & $<0.001$ \\
\hline $\mathrm{Col}$ & 1.3 & 0.0 & 1.3 & 0.1 & $<0.001$ \\
\hline BAI & 20.2 & 2.7 & 25.3 & 4.0 & $<0.001$ \\
\hline
\end{tabular}

Note: "t student test. SD: Standard Deviation; BMI: Body Mass Index; WC: Waist Circumference; WHR: Waist-Hip Ratio; WHeR: Waist-Height Ratio; Col: Conicity Index; BAI: Body Adiposity Index.

similar among all the indicators. Specificity was higher in Col, WHR and BAI. NPV was higher in WHeR and in BMI.
In women, all the indices showed a lower predictive ability. The best predictors were BMI and WHeR. They presented a higher AUC and 
Table 3. Frequency of MetS components and high anthropometric parameters according to sex. Viçosa (MG), 2012.

\begin{tabular}{|c|c|c|c|c|c|}
\hline \multirow{2}{*}{$\begin{array}{l}\text { Metabolic Syndrome components } \\
\text { and Adiposity Indices }\end{array}$} & \multicolumn{2}{|c|}{ Men } & \multicolumn{2}{|c|}{ Women } & \multirow{2}{*}{$p$} \\
\hline & $\%$ & $\mathrm{n}$ & $\%$ & $\mathrm{n}$ & \\
\hline \multicolumn{6}{|l|}{ Metabolic Syndrome Components } \\
\hline Fasting glucose & 70.4 & 112 & 72.0 & 175 & $<0.001$ \\
\hline Triglyceride levels & 29.5 & 47 & 35.8 & 87 & $<0.001$ \\
\hline High density cholesterol & 50.9 & 81 & 55.9 & 136 & $<0.001$ \\
\hline Blood pressure & 32.7 & 52 & 27.1 & 66 & $<0.001$ \\
\hline WC & 39.6 & 63 & 66.6 & 162 & $<0.001$ \\
\hline MetS & 40.2 & 647 & 63.7 & 155 & $<0.001$ \\
\hline \multicolumn{6}{|l|}{ Adiposity Index } \\
\hline BMI & 31.4 & 50 & 55.9 & 136 & $<0.001$ \\
\hline WheR & 74.8 & 119 & 96.7 & 235 & $<0.001$ \\
\hline WHR & 38.9 & 62 & 93.0 & 226 & $<0.001$ \\
\hline $\mathrm{Col}$ & 0.0 & 0 & 0.4 & 1 & 0.41 \\
\hline BAl & 3.0 & 1.89 & 6.1 & 15 & $<0.001$ \\
\hline
\end{tabular}

Note: "Pearson Chi-Square test.

WC: Waist Circumference; MetS: Metabolic Syndrome; BMI: Body Mass Index; WHeR: Waist-Height Ratio; WHR: Waist-Hip Ratio; Col: Conicity Index; BAI: Body Adiposity Index.

Table 4. The predictive ability of adiposity indicators of metabolic syndrome in elderly men and women enrolled in the Health Strategy Family Program. Viçosa (MG), 2012.

\begin{tabular}{lcccccc}
\hline Predictive Variables & AUC $(\mathrm{Cl} 195 \%)$ & Cutoff points & $\mathrm{SE}^{* *}(\mathrm{Cl} 95 \%)$ & $\mathrm{ES}^{* *}(\mathrm{Cl} 195 \%)$ & $\mathrm{PPV}^{* *}$ & $\mathrm{NPV}^{* *}$ \\
\hline Men & & & & & \\
BMI & & & & & \\
WHeR & $0.87(0.81-0.92)$ & 24.75 & $89,06(78,7-95,5)$ & $63,16(63,6-82,2)$ & 69.50 & 90.90 \\
WHR & $0,87(0,81-0,92)$ & 0.55 & $92,19(82,7-97,4)$ & $69,47(60,3-79,4)$ & 67.00 & 93.00 \\
Col & $0,86(0,79-0,91)$ & 0.98 & $81,25(64,3-86,2)$ & $75,79(72,9-89,2)$ & 69.30 & 85.70 \\
BAl & $0,81(0,74-0,87)$ & 1.32 & $71,87(60,9-83,7)$ & $76,84(67,1-84,9)$ & 67.60 & 80.20 \\
Women & $0,75(0,68-0,82)$ & 20.28 & $76,56(64,3-86,2)$ & $71,58(61,4-80,4)$ & 64.50 & 81.90 \\
BMI & & & & & \\
WHeR & $0,71(0,65-0,76)$ & 23.73 & $89,68(88,5-96,9)$ & $42,05(28,4-49,6)$ & 73.20 & 69.80 \\
WHR & $0,69(0,63-0,75)$ & 0.59 & $77,92(70,5-84,2)$ & $53,41(42,5-64,1)$ & 74.50 & 58.00 \\
Col & $0,66(0,60-0,72)$ & 0.97 & $51,61(44,7-61,0)$ & $72,73(62,2-81,7)$ & 76.90 & 46.00 \\
BAl & $0,62(0,56-0,68)$ & 1.32 & $69,03(59,1-74,4)$ & $52,27(44,7-66,3)$ & 71.80 & 48.90 \\
\hline
\end{tabular}

Note: ${ }^{*} Z$ test for comparison between areas under the curves $-p<0.001$ for males and $p=0,002$ for females. ${ }^{* *}$ Percentage. Comparison of predictive ability of BMI, WHeR, WHR, Col and BAl for MetS based on sex.

${ }^{1}$ Men: statistical difference between the area under the curve: BMl $\times$ WHeR $(p=0.857)$, BMl $\times$ WHR $(p=0.721)$, WHeR $\times$ WHR $(p=0,505)$, WHeR $\times$ Col $(p=0,016), \mathrm{WHeR} \times \mathrm{BAI}(p<0,001), \mathrm{Col} \times \mathrm{BAI}(p=0,174), \mathrm{WHR} \times \mathrm{Col}(p=0,053), \operatorname{WHR} \times \mathrm{BAI}(p=0.0151), \mathrm{BMI} \times \mathrm{Col}(p=0,127), \operatorname{BMl} \times \operatorname{BAl}(p<0,001)$, BMI $\times$ WHR $\times$ Col $(p=0,076), \operatorname{BMI} \times$ WHR $\times$ BAI $(p<0,001), \operatorname{BMI} \times$ WHR $\times$ WHeR $(0,784) .{ }^{2}$ Women: BMI $\times$ WHeR $(p=0.538), \operatorname{BMI} \times$ WHR $(p=0.233)$, WHeR $\times$ WHR $(p=0.307), W H e R \times C o l(p=0,011), W H e R \times B A I(p=0,021), \operatorname{Col} \times \operatorname{BAl}(p=0,711), W H R \times C o l(p=0.075), W H R \times B A I(p=0.620), \operatorname{BMI}$

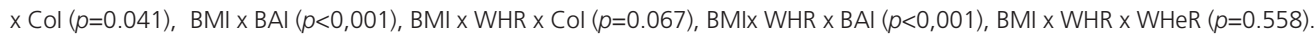

AUC: Receiver Operating Characteristic Curves Analysis; CI: Confidence Interval; SE: Sensitivity; ES: Specificity; PPV: Positive Predictive Value; NPV: Negative Predictive Value; BMI: Body Mass Index; WHeR: Waist-Height Ratio; WHR: Waist-Hip Ratio; Col: Conicity Index; BAl: Body Adiposity Index. 
were statistically different from BAl and Col, which presented a lower AUC and a lower discriminatory ability. WHR did not differ from any indicator.

$\mathrm{BMI}$ and WHeR were the most sensitive indicators in MetS diagnosis. The other indicators showed similar sensitivity values, except for WHR. Although WHR showed greater PPV, all the indices showed close values to each other. The most specific indicator was WHR and the biggest NPV was BMI, whereas the other indicators showed similar SE and NPVs.

\section{I SCUSSION}

The study showed a MetS prevalence of $54.8 \%$ in elderly individuals $(95.0 \% \mathrm{Cl}: 49.0 \%$ - 59.0\%); this prevalence was significantly higher among women. A Brazilian study of 243 elderly individuals (whose average age was $71 \pm 7$ years for women and $70 \pm 7$ years for men), predominantly female $(74.0 \%)$, conducted in Rio de Janeiro, revealed a higher overall prevalence of MetS using the same criterion diagnosis, $69.1 \%$. In the present study, the prevalence of MetS among men and women was similar, but in comparison, the prevalence among men was higher than that found in the present study, $69.8 \%$, and similar in relation to the female subjects, 68.9\% [19]. Research in Taiwan evaluated a cohort of 18,916 elderly individuals divided into three age subgroups using the Joint Interim Statement (JIS) criterion. It evidenced the increasing prevalence of MetS and its components among the age groups, particularly among women [3].

The predictive ability of adiposity indicators on MetS occurrence in men showed that although the WHeR and BMI indices have shown higher values of area under the ROC curve, the differences were not significant. The considered indices showed satisfactory and similar capacity to discriminate MetS.

In women, the predictive ability of anthropometric variables was lower than that found in men. All the indices showed moderate predictive ability and were equivalent to each other, since no AUC exceeded 0.8.

Chu et al. [20] evaluated the predictive ability of anthropometric indicators regarding MetS in elderly female adults women and found an AUC lower than 0.8 in WHeR, WHR, BMI and WC. They attributed the low predictive ability to the average age of women, approximately 72 years old. This age group has a high probability of having other cardiometabolic risk factors besides body adiposity; indicators that rely on body fat may be less predictive for this reason.

Other studies $[3,20]$ showed age and menopause as independent MetS predictors in elderly women, since the presence of MetS components increased with aging and menopausal status. According to the current study, the best MetS predictor cutoff points in WheR were 0.55 (men) and 0.59 (women). These values were higher than those recommended for adults in literature (0.5) [21]. A major agestratified MetS study performed in employees from a Chinese company found that the WHeR cutoff point (0.53) in elderly men was similar to that found in the current study. However, they found an AUC of 0.6, lower than the one found in the current research [21]. Another study on Iranian elderly men identified a higher cutoff point than the one found in the present study, 0.58 (AUC=0.68; 95\% Cl:0.60 - 0.75) [4]. A study conducted in Salvador, Brazil, with 203 elderly individuals residing in a long-term institution in Salvador, identified a cut-off point for the MetS predictor WHeR equal to that of the present study for males, 0.55 (AUC $=0.89,95 \%$ Cl:0.71-0.98), with sensitivity and specificity values of 0.92 and 0.90 , respectively [11].

Regarding women, the Chinese study found a lower cutoff point, 0.55 ( $A \cup C=0.615$ ). The current study, despite having identified a higher cutoff point, obtained the best area under the ROC curve. This study, conducted on 113 elderly women from Viçosa (MG), found a 
WHR cutoff point of 0.6 (AUC $=0.67 ; 95.0 \%$ Cl:0.58 - 0.76) in MetS, with a sensitivity of $73.3 \%$ [22], a similar result to the one found in the present study (0.59). In another Brazilian study with institutionalized elderly in Salvador, the sample consisted of $77.8 \%$ women, showing a lower cutoff point, 0.54 (AUC $=0.856, \mathrm{Cl}$ 95.0\%: $0.78-0.91)$, sensitivity of 0.84 and specificity of $0.78[11]$.

WHeR is based on the assumption that height influences body fat accumulation and distribution [23] as well as WC size, over time [24]. Hence, changes associated with aging, such as reduced height and abdominal fat deposition may influence WHeR results differently in elderly age groups $[14,22]$. As an indicator of central adiposity and given the natural changes to the body composition of the elderly, the cutoff point higher than the recommended for young adults seems to predict cardiometabolic changes in this population.

Regarding the BMI, the cutoff point evidenced by the current study to predict MetS was $24.75 \mathrm{~kg} / \mathrm{m}^{2}$ in men and $23.73 \mathrm{~kg} / \mathrm{m}^{2}$ in women. It is an index that discriminates the nutritional status, adiposity and is associated with the risk of cardiovascular diseases. The results found in the present study for both sexes were lower than the value proposed by Lipschitz [16] for elderly individuals, and lower than the value presented by The Pan American Health Organization (PAHO) [25] for adults. However, findings in the literature show consistent values with those found in the present study. Wang et al. [24] identified the cutoff point of $23.93 \mathrm{~kg} / \mathrm{m}^{2}$, but with a lower AUC value, 0,65 (95\% Cl:0.64 $-0.66)$ in men. As for elderly women, they found the value of $24.15 \mathrm{~kg} / \mathrm{m}^{2},(A \cup C=0.64 ; 95 \% \mathrm{Cl}$ : $0.61-0.67)$.

Gharipour et al. [4] identified $26.65 \mathrm{~kg} /$ $\mathrm{m}^{2}$ in elderly men, with a lower AUC value, 0,64 (95\% Cl:0.56- 0.72), sensitivity of $48 \%$ and specificity of $76 \%$.

The cutoff points identified in this study are lower than those indicated for the elderly and adult populations. Body fat accumulation and lean body mass decreases may induce an increase or a decrease regarding body mass measurements and, consequently, in BMI values. This index does not properly distinguish fat mass and lean mass. It may be less useful as an adiposity indicator among elderly people, who have more body fat at a given BMI, than it is among young individuals, due to age-related body mass reduction. Thus, BMI cannot be used as a single estimate of obesity or body fat mass in elderly individuals; it is an indicator of total body weight regarding height $[8,26]$.

The epidemiological investigation found that an increasing BMl and abdominal fat is mainly associated with high fasting glucose, triglyceride levels and blood pressure, and reduced HDL levels. Thus, a greater MetS frequency was observed in the group of overweight and obese individuals [27].

The WHR anthropometric index also proved to be useful in predicting MetS, and showed the best cutoff points: 0.98 (AUC $=0.86$; $95 \% \mathrm{Cl}: 0.79-0.91)$ and 0.97 (AUC=0.66; $95 \%$ $\mathrm{Cl}: 0.60-0.73$ ) in men and women, respectively. Regarding men, the cutoff point found in this study was lower than that suggested for adults by the WHO [15] (1.0). The cutoff point identified for women was higher than that recommended by the WHO [15] (0.85).

The study on Chinese elderly women showed a similar cutoff point to the one aimed at adults, 0.86 ( $A \cup C=0.58 ; 95 \% \mathrm{Cl}: 0.55-0.61)$ [21]. Accordingly, two studies that evaluated samples from elderly individuals and adult women identified cutoff points of 0.84 and 0.87 $[28,29]$.

Gharipour et al. [4] found a similar value (0.95) to that which was found in the present study, with an AUC of 0.64 , sensitivity of $69 \%$ and specificity of 29\%. Wang et al. (2009) [24] found a slightly lower cutting point (0.89), with AUC of 0.56 (95\% Cl:0.55 - 0.57). The area under the ROC curve found in the current study was higher than that found in the other two studies. 
WHR is a useful parameter in the evaluation of body fat distribution. WC and HC reflect different aspects of body composition and configure independent and opposite results in determining the risk of cardiometabolic diseases and risk factors. Thus, narrow waists and wide hips are associated with protection against cardiometabolic diseases. The literature suggests that WHR may be a less valid measure, since this indicator does not detect waist and hip proportional changes [30].

Col and BAI were considered satisfactory MetS predictors among men and weak predictors among women. Regarding Col, the widely used reference, intended for adults, it indicates values above 1.73 as risk of developing cardiovascular diseases [31].

The main studies performed to identify the association between Col and cardiometabolic risk factors were conducted by Pitanga and collaborators in Brazil [12,32]. However, their sample was mainly composed of adults and a few elderly individuals, and it was not stratified by age to investigate the predictive ability of anthropometric indicators on high coronary risk. A study conducted in Viçosa (MG) comprising 113 elderly women obtained the same mean Col found in the present study, which is similar to the identified cutoff point [22].

$\mathrm{BAl}$ is a recent anthropometric indicator, which was suggested as an alternative parameter to BMI in body fat assessment and it reflects a direct estimate of body fat percentage. The authors did not propose a cutoff point for this index. There is still controversy about its effectiveness in adiposity assessment [33,34].

The present study found the BAI cutoff point of $20.28 \%$ in elderly men and $24.01 \%$ in elderly women. Studies have found that BAI overestimates obesity in men and shows slight underestimation in women $[33,34]$ regarding the ability to discriminate individuals with higher or lower fat percentage. Further studies are needed to assess BAl effectiveness as well as the determinations of sensitive cutoff points in elderly individuals.

It is possible to see that the cutoff points found in the current study for anthropometric measurements in male and female elderly corroborate other findings in the literature. However, the differences found among values may be attributed to regional ethnic differences that influence people's life habits and determine peculiarities in the individuals' body composition [34].

This study's strength was the fact that a single trained professional performed all the anthropometric measurements, thus minimizing inter and intrapersonal variations.

Some limitations should be mentioned. The first concerns the sample representativeness, which does not comprise all elderly individuals from Viçosa, since the source population was composed of people enrolled in the FHS Program. Several diagnostic criteria suggested by different organizations to classify MetS showed differences in their components and/or in the adopted cutoff point values. It is difficult to compare these studies.

\section{CONCLUSION}

WHeR and BMI are good MetS predictors among elderly individuals, especially among men. Regarding Col and BAI, further studies are needed to elucidate the importance of these indicators in predicting MetS among elderly individuals.

It was observed that the cutoff points of anthropometric indicators identified in elderly women were higher, therefore more specific than those suggested for younger adults. The cutoff points identified in elderly men were lower, thus more sensitive in comparison to those recommended for younger adults.

This study's results corroborate the assumption that anthropometric measurements are of great value in epidemiological studies and 
in clinical practice since they are simple to use, non-invasive, low cost and are relatively easy to interpret.

\section{CONTRIBUTORS}

KBD MORAIS, AQ RIBEIRO contributed to all stages of conception and design of this study. KO MARTINHO, FS FRANCO and MC PESSOA contributed to the analysis of results and manuscript writing.

\section{REFERENCES}

1. Martinho KO, Dantas EHM, Longo GZ, Ribeiro AQ, PereiraET, Franco FS, etal. Comparison of functional autonomy with associated sociodemographic factors, lifestyle, chronic diseases (CD) and neuropsychiatric factors in elderly patients with or without the metabolic syndrome (MS). Arch Gerontol Geriatr. 2013;57(2):151-5. http://dx.doi. org/10.1016/j.archger.2013.04.005

2. Hu H, Kurotani K, Sasaki N, Murakami T, Shimizu C, Shimizu M, et al. Optimal waist circumference cut-off points and ability of different metabolic syndrome criteria for predicting diabetes in Japanese men and women: Japan epidemiology collaboration on occupational health study. BMC Public Health. 2016;16(1):220. http://dx.doi.org/10. 1186/s12889-016-2856-9

3. Chuang $T-J$, Huang $C-L$, Lee $C-H$, Hsieh $C-H$, Hung $Y-J$, Hung C-F, et al. The differences of metabolic syndrome in elderly subgroups: A special focus on young-old, old-old and oldest old. Arch Gerontol Geriatr. 2016;65:92-7. http://dx.doi.org/10.1016/j. archger.2016.03.008

4. Gharipour $M$, Sadeghi M, Dianatkhah $M$, Bidmeshgi S, Ahmadi A, Tahri M, et al. The cut-off values of anthropometric indices for identifying subjects at risk for metabolic syndrome in Iranian elderly men. J Obes. 2014;2014:6. http://dx.doi.org/10. $1155 \% 2 F 2014 \% 2 F 907149$

5. Corrêa MM, Thumé E, De Oliveira ERA, Tomasi E. Performance of the waist-to-height ratio in identifying obesity and predicting non-communicable diseases in the elderly population: A systematic literature review. Arch Gerontol Geriatr. 2016;65:174-82. http://dx.doi.org/10.1016/j.archger.2016.03.021

6. Macias N, Quezada AD, Flores M, Valencia ME, Denova-Gutiérrez E, Quiterio-Trenado $\mathrm{M}$, et al. Accuracy of body fat percent and adiposity indicators cut off values to detect metabolic risk factors in a sample of Mexican adults. BMC Public Health. 2014;14(1):341. http://dx.doi.org/10.1186/1471-24 58-14-341
7. Santos PCM, Ferreira ALL, Mori RMSC. Frequência da Síndrome Metabólica em idosos cadastrados no Programa Saúde do Idoso de uma Unidade Municipal de Saúde de Belém-PA. Rev Assoc Bras Nutr. 2017 [acesso 2017 mar 3];8(1):75-81. Disponível em: https://rasbran.emnuvens.com.br/ rasbran/article/view/338/162

8. Delvarianzadeh $M$, Abbasian $M$, Khosravi $F$, Ebrahimi H, Ebrahimi MH, Fazli M. Appropriate anthropometric indices of obesity and overweight for diagnosis of metabolic syndrome and its relationship with oxidative stress. Diabetes Metab Syndr: Clin Res Rev. 2017;11:S907-S11.

9. Wang $H$, Liu A, Zhao T, Gong $X$, Pang T, Zhou $Y$, et al. Comparison of anthropometric indices for predicting the risk of metabolic syndrome and its components in Chinese adults: A prospective, longitudinal study. BMJ Open. 2017;7(9):e016062. http://dx.doi.org/10.1136/bmjopen-2017-016062

10. Oliveira CC, Costa ED, Roriz AKC, Ramos LB, Gomes Neto M. Predictors of Metabolic Syndrome in the elderly: A review. Int I Cardiol Sci. 2017;30(4):343-53. http://dx.doi.org/10.59 35/2359-4802.20170059

11. Oliveira CC, RorizAKC, Ramos LB, NetoMG. Indicators of adiposity predictors of Metabolic Syndrome in the elderly. Ann Nutr Metab. 2017 [cited 2017 Mar 25];70(1):9-15. Available from: https://www.ncbi. nlm.nih.gov/pubmed/28103600?dopt=Abstract

12. Haun DR, Pitanga FJG, lessa I. Razão cintura/estatura comparado a outros indicadores antropomé-tricos de obesidade como preditor de risco coronariano elevado. Rev Assoc Med Bras. 2009;55(6):705-11. http://dx.doi.org/10.1590/S0104-42302009000 600015

13. Fogal $A S$, Ribeiro $A Q$, Priori SE, Franceschini SCC. Prevalência de síndrome metabólica em idosos: uma revisão sistemática. Rev Assoc Bras Nutr. 2014 [acesso 2017 abr 8];6(1):29-35. Disponível em: https://rasbran.emnuvens.com.br/rasbran/article/ viewFile/174/126

14. World Health Organization. Physical status: The use and interpretation of anthropometry: Report of a WHO Expert Committee. Geneva: World Health Organization; 1995 [cited 2017 Apr. 8]. Available from: http://www.who.int/iris/handle/1 0665/37003

15. World Health Organization. Obesity: Preventing and managing the global epidemic. Report of the WHO Consultation on Obesity. Geneva: WHO; 1998.

16. Lipschitz DA. Screening for nutritional status in the elderly. Prim Care. 1994 [cited 2017 May 17];21(1):55. Available from: https://www.ncbi.nlm. nih.gov/pubmed/8197257

17. Brasil. Sociedade Brasileira de Cardiologia. VII Diretriz Brasileira de Hipertensão Arterial. Arq Bras Cardiol. 2016 [acesso 2017 maio 29];107(3). 
Disponível em: http://publicacoes.cardiol.br/2014/ diretrizes/2016/05_HIPERTENSAO_ARTERIAL.pdf

18. Alberti KG, Eckel RH, Grundy SM, Zimmet PZ, Cleeman JI, Donato KA, et al. Harmonizing the metabolic syndrome: A joint interim statement of the International Diabetes Federation Task Force on Epidemiology and Prevention; National Heart, Lung, and Blood Institute; American Heart Association; World Heart Federation; International Atherosclerosis Society; and International Association for the Study of Obesity. Circulation. 2009;120(16):1640-5. http://dx.doi.org/10.1161/ CIRCULATIONAHA.109.192644

19. Saad MAN, Cardoso GP, Martins WA, Velarde LGC, Cruz Filho RA. Prevalence of Metabolic Syndrome in elderly and agreement among four diagnostic criteria. Arq Bras Cardiol. 2014;102(3):263-9. http://dx.doi.org/10.5935\%2Fabc.20140013

20. Chu FL, Hsu CH, Jeng C. Low predictability of anthropometric indicators of obesity in metabolic syndrome risks among elderly women. Arch Gerontol Geriatr. 2012;55(3):718-23. http://dx.doi. org/10.1016/j.archger.2012.02.005

21. Hsieh SD, Yoshinaga H. Waist/Height Ratio as a simple and useful predictor of coronary heart disease risk factors in women. Intern Med. 1995;34(12):1147-52. http://dx.doi.org/10.2169/ internalmedicine.34.1147

22. Paula HAA, Ribeiro RCL, Rosado LEFPL, Pereira RSF, Franceschini SCC. Comparação de diferentes critérios de definição para diagnóstico de síndrome metabólica em idosas. Arq Bras Cardiol. 2010;95(3):346-53. http://dx.doi.org/10.1590/S006 6-782X2010005000100

23. Eshtiaghi R, Esteghamati A, Nakhjavani M. Menopause is an independent predictor of metabolic syndrome in Iranian women. Maturitas. 2010;65(3):262-6. http://dx.doi.org/10.1016/j.maturitas.2009.11.004

24. Wang F, Wu S, Song $Y$, Tang $X$, Marshall $R$, Liang $M$, et al. Waist circumference, body mass index and waist to hip ratio for prediction of the metabolic syndrome in Chinese. Nutr Metab Cardiovasc Dis. 2009;19(8):542-7. http://dx.doi. org/10.1016/j.numecd.2008.11.006

25. Organización Panamericana de la Salud. División de Promoción y Protección de la Salud. Encuesta multicentrica salud bienestar y envejecimiento (SABE) en América Latina: informe preliminar / Multicenter survey aging, health and wellbeing in Latin América and the Caribbean (SABE): preliminary report. Presentado en: Reunión del Comité Asesor de Investigaciónes en Salud 2001 [acceso 2017 jun 2];36. Disponible en: http:// www1.paho.org/Spanish/HDP/HDR/CAIS-01-05. PDF
26. Jahanlou AS, Kouzekanani K. The accuracy of Body Mass Index and Gallagher's Classification in detecting obesity among Iranians. Iran J Med Sci. 2016 [cited 2017 Jul 18];41(4):288-95. Available from: http://www.ncbi.nlm.nih.gov/pmc/articles/ PMC 4912647/

27. Ortiz-Rodríguez MA, Yáñez-Velasco L, Carnevale A, Romero-Hidalgo S, Bernal D, Aguilar-Salinas C, et al. Prevalence of metabolic syndrome among elderly Mexicans. Arq Bras Cardiol. 2017 [cited 2017 Aug 2];73:288-93. Available from: https:// www.ncbi.nlm.nih.gov/pubmed/28910752

28. Almeida RT, Almeida MMG, Araújo TM. Obesidade abdominal e risco cardiovascular: desempenho de indicadores antropométricos em mulheres. Arq Bras Cardiol. 2009;92(5):375-80. http://dx.doi. org/10.1590/S0066-782X2009000500007

29. Gharakhanlou R, Farzad B, Agha-Alinejad $H$, Steffen LM, Bayati M. Medidas antropométricas como preditoras de fatores de risco cardiovascular na população urbana do Irã. Arq Bras Cardiol. 2012;98(2):126-35. http://dx.doi.org/10.1590/S00 66-782X2012005000007

30. Vasques ACJ, Rosado LEFPL, Rosado GP, Ribeiro $\mathrm{RCL}$, Franceschini SCC, Geloneze B, et al. Diferentes aferições do diâmetro abdominal sagital e do perímetro da cintura na predição do HOMA-IR. Arq Bras Cardiol. 2009;93(5):511-8. http://dx.doi. org/10.1590/S0066-782X2009005000001

31. Valdez R, Seidell JC, Ahn YI, Weiss KM. A new index of abdominal adiposity as an indicator of risk for cardiovascular disease: A cross-population study. Int J Obes Relat Metab Disord. 1993 [cited 2017 Aug 7];17(2):77-82. Available from: https:// www.ncbi.nlm.nih.gov/pubmed/8384168

32. Pitanga FJG, Lessa I. Razão cintura-estatura como discriminador do risco coronariano de adultos. Rev Assoc Med Bras. 2006;52(3):157-61. http:// dx.doi.org/10.1590/S0104-42302006000300016

33. López AA, Cespedes ML, Vicente T, Tomas $M$, Bennasar-Veny M, Tauler $\mathrm{P}$, et al. Body Adiposity Index utilization in a Spanish mediterranean population: Comparison with the Body Mass Index. PLoS One. 2012;7(4):e35281. http://dx.doi. org/10.1371\%2Fjournal.pone.0035281

34. Bennasar Veny M, Lopez Gonzalez AA, Tauler $P_{1}$ Cespedes ML, Vicente Herrero T, Yañez A, et al. Body Adiposity Index and cardiovascular health risk factors in Caucasians: A comparison with the Body Mass Index and others. PLoS One. 2013;8(5):e63999. http://dx.doi.org/10.1371\%2 Fjournal.pone.0063999

Received: September 29, 2017 Final version: February 2, 2018 Approved: March 13, 2018 